\title{
Systematic manipulation of CS-US pairings in negative CS-US correlation procedures in rats
}

\author{
ELIZABETH S. WITCHER and JOHN J. B. AYRES \\ University of Massachusetts, Amherst, Massachusetts 01003
}

\begin{abstract}
Male albino rats were exposed to negative correlations of tone CSs and shock USs. When the number of CSs and unpaired USs was held constant, the ability of the CS to resist subsequent excitatory conditioning declined as a function of the number or proportion of CSs paired with USs; so, too, did the ability of the CS to disrupt excitation to a second CS. In one treatment, in which the rate of USs in CS presence approached that in CS absence, the CS significantly enhanced excitation to a second CS. It is concluded that the rate of USs in CS presence need not be zero for a negative correlation to produce inhibitory effects. Also discussed is the possibility that positive and negative correlation procedures may have asymmetrical effects, at least preasymptotically.
\end{abstract}

According to a contingency formulation of Pavlovian conditioning (Rescorla, 1967), excitatory conditioning results when conditioned stimuli (CSs) and unconditioned stimuli (USs) are positively correlated; the more positive the correlation, the greater the excitatory conditioning. Similarly, inhibitory conditioning results when CSs and USs are negatively correlated; the more negative the correlation, the greater the inhibitory conditioning.

Operationally, the correlation between the CS and US is defined in terms of the relative rate of US presentation in CS presence and in its absence. If that rate is higher in CS presence than in CS absence, then the stimuli are said to be positively correlated; if the rate is higher in CS absence than in CS presence, then the stimuli are said to be negatively correlated.

Empirical evidence that excitatory conditioning does, indeed, covary with the degree of positive correlation was presented by Rescorla (1968); and evidence for the symmetrical point, that inhibitory conditioning covaries with the degree of negative correlation, was subsequently presented by Rescorla (1969a). It is interesting, however, that these experiments on excitatory and inhibitory conditioning were not conducted symmetrically.

Specifically, the negative correlation experiments (Rescorla, 1969a) entailed two procedural practices that had no symmetrical counterpart in the positive

Experiments 1 and 2 are from a thesis submitted by Elizabeth S. Witcher to the University of Massachusetts, Amherst, in partial fulfillment of the requirements of the MS degree. The exploratory work described in the text was also conducted by E. S. Witcher. Experiment 3 was conducted by Carole Cioffi. The research was guided by John J. B. Ayres and was supported by Grant GB 36982 awarded to him by the National Science Foundation and by Grant MH28226-02 from the National Institute of Mental Health. Reprints may be obtained from John J. B. Ayres, Psychology Department, Middlesex House, University of Massachusetts, Amherst, Massachusetts 01003. correlation experiments (Rescorla, 1968). First, in the negative correlation treatments, the US rate was never allowed to exceed zero in CS presence. The parallel in the positive correlation treatments would be never to allow the US rate to exceed zero in CS absence; yet, in the positive correlation experiments, this rate was systematically manipulated. Second, in the negative correlation treatments, the US rate was zero in a 2-min period following CS presentation. The parallel in the positive correlation treatments would be to set the rate of USs in the 2-min post-CS period equal to the rate of USs in the CS itself. Rescorla (1968) did not follow this practice in his experiments on positive correlations.

From the point of view of Pavlov (1960), who asserted that inhibition was more "labile" than excitation, the two practices just described seem quite reasonable. That is, one might fear that a nonzero rate of USs in CS presence or following the CS might totally destroy conditioned inhibition, even if the correlation between CS and US were negative. However, this apprehension would not follow from the contingency view. There is no principle within the contingency formulation from which it can be deduced that a nonzero rate of USs in CS presence should have a greater detrimental effect on conditioned inhibition than a nonzero rate of USs in CS absence should have on conditioned excitation.

Related to contingency theory is the cognitive view held by many writers (e.g., Mackintosh, 1974) that animals "learn about" the correlations to which they are exposed. Once again, it is not clear from such statements why it should be harder to "learn about" negative correlations than positive ones; nor is it clear how this cognitive view might lead one to design positive and negative correlation experiments containing the procedural asymmetries described above. 
The present paper reports the results of a negative correlation experiment in which one of the procedural asymmetries described was eliminated. Unlike Rescorla (1969a), we did allow the US rate to exceed zero in CS presence; indeed, we systematically manipulated that rate while holding constant the US rate in CS absence. Like Rescorla (1969a), however, we did not allow the US rate to exceed zero in the 2-min post-CS period. We were reluctant to depart simultaneously from Rescorla's procedures in two theoretically major ways.

\section{EXPERIMENT 1}

Experiment 1 was a parametric manipulation of the degree of negative correlation between tone CSs and electric shock USs. Inhibition conditioned to the CS was assessed using a retardation test. The logic of this test is that if a CS is inhibitory, it should resist subsequent excitatory conditioning in comparison to a relatively neutral CS (Rescorla, 1969b). The measure of excitation, in turn, was the amount of suppression of free-operant barpress behavior evoked by the CS once it was reinforced.

\section{Method}

Subjects

The subjects were 42 male albino Sprague-Dawley rats from the Holtzman Co., Madison, Wisconsin; they were 90-100 days old at the start of the experiment. They were housed individually and maintained at $80 \%$ of their free-feeding weights throughout experimentation.

\begin{abstract}
Apparatus
Six Gerbrands operant conditioning chambers with left-side dipper feeders were housed in .61-m cubes of $13-\mathrm{mm}$ plywood lined with acoustical tile. The CS was a $1,000-\mathrm{Hz}$ tone. It was presented through a $10-\mathrm{cm}$ speaker mounted on the chamber lid, and it raised the ambient noise level in the boxes from approximately 71 to $84 \mathrm{~dB}$ (re $20 \mu \mathrm{N} / \mathrm{m}^{2}$ ). Scrambled grid-shock USs were provided by six Grason-Stadler shock sources (Models E1064GS and 700 ). The chamber was illuminated by a $28-\mathrm{V}$ cue light, operated at $6.5 \mathrm{~V}$ and located $9.5 \mathrm{~cm}$ above the dipper opening. Barpressing, the response to be suppressed by CS presentations, was reinforced with 4-sec presentations of a .1-ml dipper cup containing $32 \%$ sucrose (by weight).
\end{abstract}

\section{Procedure}

Preliminary training. In the first session, the rats were shaped to barpress. The session ended for each rat when it made $\mathbf{5 0}$ responses, each reinforced. Five daily 2 -h sessions then followed, with a VI 2-min schedule of reinforcement in effect. In the initial VI session, however, reinforcement was delivered on a VI 1 -min schedule for the first $20 \mathrm{~min}$.

Inhibitory conditioning. This phase of the experiment was designed to establish a tone CS as a conditioned inhibitor of fear in some groups of rats while leaving it relatively neutral for others. Five daily 2-h conditioning sessions were given, during which barpressing was prevented by a four-walled Masonite insert with 19-mm vertical black and white stripes. For six groups of six rats, there were $122-\mathrm{min}, 1,000-\mathrm{Hz}$ tone CSs per session. For three of these groups, Groups $0-0,0-.1$, and $0-.8$, shock USs occurred neither during the CS nor in the 2-min period following the CS. Throughout the rest of the session, .5-sec 1-mA shock USs were randomly distributed at rates of $0, .1$, and .8 per 2 -min period for Groups $0-0,0-1$, and $0-.8$, respectively. Three additional groups, Groups .1-.8, .2-.8, and .6-.8, were identical to Group $0-.8$ except that shocks were randomly distributed throughout 2 -min CS periods at a rate of $.1, .2$, and .6 per period, respectively. A seventh group of six rats, Group Naive, was exposed to the apparatus in five daily 2 -h sessions, like the other groups, but received no experience with either tones or shocks prior to the testing phase of the experiment. Table 1 shows the exact number of CSs, unpaired USs, and CS-US pairings experienced by each group over the 5 days of conditioning.

Recovery. Two daily 2-h baseline recovery sessions began on the day following conditioning. In these sessions, the chamber inserts were removed and the rats were returned to the VI 2-min barpress schedule. Neither CSs nor USs were presented. Thus, this phase permitted barpress rates, depressed by shock presentations, to return to their normal levels before the retardation test.

Retardation testing. In each of the next six daily 2 -h sessions, four 2 -min tone CSs were presented while the rats barpressed on the VI schedule. A random two of the four CSs per day terminated with the onset of a .5-sec 1-mA shock. Conditioned suppression to the tone was assessed in terms of the Annau-Kamin (1961) suppression ratio, $D /(B+D)$. Here, $D$ denotes the response rate during the $\mathrm{CS}$ and $\mathrm{B}$ the response rate in the 2-min period before the CS. With this ratio, a score of 0 indicates strong suppression or excitatory conditioning, while one of .50 indicates no effect.

\section{Results}

Figure 1 shows the mean suppression ratios for each group for the 6 days of retardation testing. Because of the large number of groups, the data are displayed in two panels. Panel A presents the data for Groups $0-.1,0-.8, .1-.8$, and Naive. Panel B plots the data for Groups $0-0, .2-.8, .6-.8$, and Naive. The results of Group Naive are plotted in both panels to provide a common reference point, thereby facilitating between-panel comparisons.

As suggested by the figure, all seven groups acquired excitation to the tonal CS, but at different rates. A Kruskal-Wallis analysis of variance performed on the suppression ratios averaged across the 6 days of testing found reliable differences among groups $(\mathrm{H}=22, \mathrm{p}<.005)$; and experimental vs. control group comparisons (see Wilcoxon \& Wilcox, 1964) found weaker suppression in Groups 0-.1, $0-.8$, and .1-.8 (see Panel A) than in Group Naive (ps $<.05) .{ }^{1}$ This is a result that would be expected from the hypothesis that the $0-.1,0-.8$, and $.1-.8$ treatments yield an inhibitory CS. In addition to the

Table 1

Number of CSs, Pairings, and USs Alone Experienced Over Five Sessions of Inhibitory Conditioning

\begin{tabular}{cccc}
\hline Group & CSs & Pairings & USs Alone \\
\hline Naive & 0 & 0 & 0 \\
$0-0$ & 60 & 0 & 0 \\
$0-.1$ & 60 & 0 & 18 \\
$0-.8$ & 60 & 0 & 144 \\
$.1-.8$ & 60 & 6 & 144 \\
$.2-.8$ & 60 & 12 & 144 \\
$.6-.8$ & 60 & 36 & 144 \\
\hline
\end{tabular}



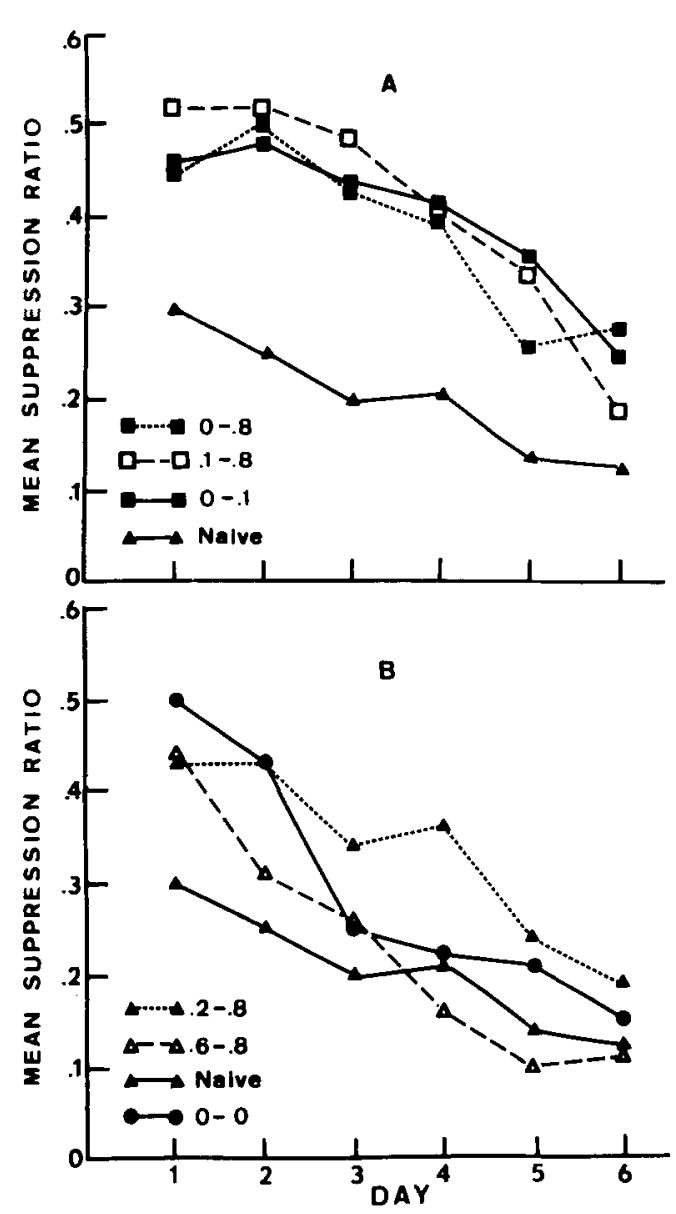

Figure 1. Mean suppression ratios for 6 days of retardation testing in Experiment 1. Panel A: Groups 0-.1, 0-.8, .1-.8, and Naive. Panel B: Groups 0-0, .2-.8, .6-.8, and Naive.

Kruskal-Wallis analysis of variance, a separate analysis was conducted using the data from only Groups 0-.8, .1-.8, .2-.8, and .6-.8. These groups all received the same number of CSs and unpaired USs; they differed only in the number or proportion of their CSs that were paired with USs. Assuming that inhibitory conditioning should weaken in proportion to the number or proportion of CSs paired with USs, it can be predicted that retardation should have decreased across the four groups in the order listed above. Consistent with this prediction, the mean suppression ratios averaged over all 6 days of testing for Groups $0-.8, .1-.8, .2-.8$, and .6-.8 were $.41, .42, .35$, and .23 , respectively. A Jonckheere's test against an ordered hypothesis (Hollander \& Wolfe, 1973, pp. 120-123) found this ordering to be highly reliable $(\mathrm{J}=157.5, \mathrm{p}<.006)$. Wilcoxon rank sums tests showed that Groups $0-.8$ and $.1-.8$ suppressed less (were more retarded) than Group .6-.8 (Ts $\leqslant 27$, ps $<.05$ ).

Based on previous work (e.g., Lubow \& Moore, 1959), we might also have expected some retardation in the group preexposed to CSs alone (Group 0-0). Figure 1, Panel B, suggests that there may, indeed, have been some retardation in this group, particularly on Days 1 and 2; however, this effect was not reliable, even on those days. One possible reason for the failure of this effect to achieve reliability is that there was a context change between experimental treatment and testing. Experimental treatment was conducted with the rats blocked from the bar by Masonite inserts. Testing was conducted while the rats were barpressing with the inserts removed. There is evidence that the effects of CS preexposure are context specific (e.g., Lubow, Rifkin, \& Alek, 1976; Wagner, 1976).

\section{Discussion}

When the number of CSs and unpaired USs was held constant in several negative correlation treatments, retardation tended to decrease as a function of the number or proportion of CSs paired with USs. This result is predicted by numerous views of conditioning (e.g., Rescorla, 1967; Rescorla \& Wagner, 1972), but until now has not been confirmed because there has been no systematic manipulation of the relative frequency of USs in CS presence within a negative correlation procedure.

Although retardation declined with increases in CS-US pairings, at least one negative correlation group that received some CS-US pairings, Group . 1-.8, still showed retarded acquisition. Groups 0-.1 and $0-.8$ likewise showed retarded acquisition; and this result, of course, is consistent with previous demonstrations that excitatory conditioning is retarded following explicitly unpaired presentations of CSs and USs (e.g., Rescorla 1969a).

Although the retarded acquisition in Groups .1-.8, $0-.8$, and $0-.1$ is consistent with the idea that these negative correlations produced inhibitory CSs, the data do not require this interpretation. Other interpretations are also possible. Perhaps the retardation resulted from US-alone preexposure (e.g., Mis \& J. W. Moore, 1973), or perhaps the retardation resulted from CS-alone preexposure (e.g., Lubow \& A. U. Moore, 1959). Since all the groups that showed significant retardation received some CSs unpaired with USs and some USs unpaired with CSs, their retardation might have been due to either or both of these factors. The remaining experiments sought to assess the plausibility of these alternative hypotheses.

\section{EXPERIMENT 2}

In the preceding study, a negative correlation between a tone CS and a shock US led to retarded acquisition of conditioned suppresion to the tone in Groups 0-.1,0-.8, and .1-.8. If this retardation were due to US-alone preexposure, then there should be 
no reason why the retardation should be specific to the tone. Retardation would also be expected if some other stimulus, for example a light, were subsequently paired with shock. Among other things, Experiment 2 provided a test of this possibility.

Experiment 2 also provided a test of the possibility that the retardation could have been due to CS-alone preexposure. Although we did not find a significant retardation effect in our Group 0-0, which received only CS-alone preexposure, we did find a tendency in that direction. It is widely agreed (e.g., Halgren, 1974; Reiss \& Wagner, 1972; Rescorla, 1971) that the retardation typically produced by CS-alone preexposure results from an attentional decrement. The subject appears slow to attend to the preexposed CS. To test this possibility, Experiment 2 employed a summation test in which the tone from the negative correlation treatment was compounded with an excitatory light. If the tone had acquired inhibitory properties, then it should oppose the excitation conditioned to the light and thus weaken the conditioned suppression that the light normally evoked. The tone could not disrupt suppression to the light unless the tone were attended to. Such a result would therefore imply that the retardation seen earlier was not due to lack of attention to the tone (cf. Rescorla, 1969b).

Assuming that conditioned inhibition was responsible for the retardation of Experiment 1, we should expect the tone to weaken suppression to an excitatory light following the $0-.1,0-.8$, and $.1-.8$ treatments. However, it is not entirely clear what we should expect following the $.2-.8$ and $.6-.8$ treatments. Ayres, Benedict, and Witcher (1975) found that slightly negative CS-US correlations yielded evidence of excitatory conditioning. For example, the treatments given to Groups $5 \mathrm{P}$ and $3 \mathrm{P}$ in their Experiment 1 and to Group 7P-OD-EUS in their Experiment 3 could be described, respectively, as .08-.14, $.05-.19$, and $.12-.32$ negative correlations. (The rate of shock in CS presence and absence can be determined from the display provided by Ayres et al. on p. 98.) All of these treatments produced an apparently excitatory CS.

It seems possible therefore that a slight negative correlation such as the .6-.8 treatment of Experiment 1 might also produce an excitatory CS. Even though Group .6-.8 showed no evidence of excitatory "savings" in the retardation test, it might show an excitatory summation effect in a summation test. Reberg (1972) has shown that a mildly excitatory stimulus may not produce conditioned suppression when presented alone but, when compounded with a second, moderately excitatory stimulus may increase the level of suppression to that stimulus.

Subject and Apparatus

\section{Method}

Forty-two naive rats, similar to those of Experiment 1, served in the same apparatus.

\section{Procedure}

Preliminary training and inhibitory training were unchanged. Recovery training was also similar to that of Experiment 1, but was conducted for 3 days instead of 2 .

Following recovery, a second stimulus was established as a conditioned excitor to be used later in the summation test. This stimulus was a flashing light created by changing the voltage across the cue light from 6.5 to $26 \mathrm{~V}$ once per second. In each of three daily 2-h sessions of this excitatory conditioning phase, four 2-min presentations of the flashing light were superimposed upon VI responding. A random two of the four light CSs each day terminated with the onset of a .5-sec 1-mA shock.

The final phase of the experiment was the summation test. In each of two daily 2-h sessions, four 2-min test CSs were superimposed on VI responding. On two of the trials, the flashing light was presented alone. On the other two trials, the light was presented in compound with the tone CS. No shocks were delivered at any time. The order of presentation of light-alone and light + tone compounds was counterbalanced across the two test sessions. On Test Day 1, the order of stimuli was light, compound, compound, light. On Test Day 2, the order was compound, light, light, compound.

\section{Results and Discussion}

During excitatory conditioning to the light, the seven groups acquired suppression at similar rates; and, on the last day of light training, they exhibited mean suppression ratios below .20 that did not differ significantly. These results are important in showing that the retarded acquisition of Experiment 1 was specific to the tone. It was not due to some general deficit in learning produced, for example, by US preexposure.

Based on theoretical considerations as well as on the retardation data of Experiment 1, we would expect the inhibitory effects of the tone to decline across Groups $0-.8, .1-.8, .2-.8$, and .6-.8. Table 2 presents data bearing on this prediction. It shows the groups' mean suppression ratios on light-alone and light + tone compound trials on each day of testing. Note that on Day 1 the mean suppression ratio to the compound minus the mean to the light alone for the four groups in the order listed above was $.08, .02$, 0 , and -.06 . A Jonckheere's test against an ordered hypothesis showed this ordering to be highly reliable $(\mathrm{J}=166.5, \mathrm{p}<.005)$. Wilcoxon rank sums tests showed that Groups $0-.8$ and $.1-.8$ differed from Group $.6-.8$ (Ts $\leqslant 25$, ps $<.025$ ). These results thus parallel those of the retardation test.

Table 2

Group Mean Suppression Ratios on Light-Alone (L) and Light + Tone (LT) Trials on Both Days of Summation Testing in Experiment 2

\begin{tabular}{cccccc} 
& \multicolumn{2}{c}{ Day 1 } & & \multicolumn{2}{c}{ Day 2 } \\
\cline { 2 - 3 } \cline { 5 - 5 } Group & L & LT & & L & LT \\
\hline $0-.1$ & .24 & .24 & .34 & .31 \\
$0-.8$ & .26 & .34 & .38 & .36 \\
$.1-.8$ & .16 & .18 & .30 & .28 \\
$.2-.8$ & .20 & .20 & .39 & .34 \\
$.6-.8$ & .20 & .14 & .31 & .24 \\
$0-0$ & .25 & .26 & .37 & .35 \\
Naive & .22 & .22 & .32 & .36 \\
\hline
\end{tabular}


To determine whether the tone significantly altered suppression to the light in any of the groups of the experiment, Wilcoxon signed ranks tests were conducted. On Day 1, the tone significantly weakened suppression to the light in Group $0-.8$ and significantly increased suppression to the light in Group .6-.8 (Wilcoxon Ts $\leqslant 2$, ps $\leqslant .05$ ). Both of these differences, although quite small, were also reliable when the data were averaged over both days (Ts $\leqslant 2$, ps $\leqslant .05$ ). On Day 2 , the tone significantly increased suppression to the light in Group .2-.8 $(\mathrm{T}=0$, $\mathrm{p}<.025$ ); but this effect was not reliable when the data were averaged over both days.

Taken together with the results of the retardation test, the summation results show clearly that the tone acquired inhibitory properties for Group $0-.8$. They also suggest that the tone became mildly excitatory for Group .6-.8. The results for Group .2-.8 are not clear. Based on the results of Ayres et al. (1975), we might have predicted some very slight excitation in this group, but we would not expect excitation only on the 2nd day of summation testing. It seems possible therefore, that this result reflects a Type I error.

The results of Groups .1-.8 and 0-.1 can be interpreted in either of two ways. Since the tone did not reliably weaken suppression to the light in the summation test for these groups, one conclusion might be that the retardation produced by these treatments in Experiment 1 was not due to conditioned inhibition; instead, rats in these groups merely came to ignore the tone CS (see Rescorla, 1969b). The second interpretation might be that the retardation really was produced by conditioned inhibition but the summation test was not sensitive enough to detect it. The following experiment was designed to permit a choice between these alternatives with respect to the $.1-8$ negative correlation. We focused on that treatment because it was the only one containing some USs in CS presence that seemed likely to produce an inhibitory summation effect.

\section{EXPERIMENT 3}

The purpose of this experiment was to reassess the effects of the .1-.8 negative correlation using a summation test that, hopefully, would be more sensitive. Before conducting the experiment, we performed two exploratory studies in a search for such a test.

The first of these studies reexamined the effects of the $0-.8$ negative correlation using procedures identical to those of Experiment 2, except during the light conditioning phase. Here we increased the number of days of light conditioning (from 3 days to 6 days), the percentage of reinforced trials (from $50 \%$ to $75 \%$ ), and the light-flash rate (from $1 / \mathrm{sec}$ to $2 / \mathrm{sec}$ ) in an effort to increase suppression to the light so that opposition to that suppression by the tone might be more readily detected in summation testing. These manipulations were unsuccessful; nevertheless, the tone did reliably oppose suppression to the light in each of three groups of six rats given the $0-.8$ negative correlation treatment. The magnitude and reliability of these effects were similar to those reported for Group 0-.8 in Experiment 2.

The second exploratory study used a summation savings test similar to that used by Rescorla (1971). It assessed the rate at which three groups of 12 rats learned an $\mathrm{A}+\mathrm{AB}-$ discrimination in which stimulus $A$, paired with shock, was superimposed on a barpress baseline, and in which the compound stimulus, AB, was superimposed without shocks. For all three groups, stimulus $A$ was the flashing light and stimulus $B$ was the tone. Prior to this discrimination training, stimulus $B$ had undergone the $0-.8$ treatment for one group and the $0-0$ treatment for another; it was unexperienced by a third (Group Naive). The results were that Group 0-.8 learned this discrimination the fastest, followed by Groups Naive and 0-0, in that order. Differences among groups were very small but were marginally reliable.

Note that Group 0-.8 could not have learned the $\mathrm{A}+\mathrm{AB}$ - discrimination faster than Group Naive if the 0-.8 treatment had produced an attentional decrement to the target stimulus, B. Indirectly, this finding also suggests that Group .1-.8 did not suffer an attentional decrement either, since this group received even fewer unpaired CSs than Group 0-.8. Nevertheless, the following experiment sought more direct evidence on this point.

Since, in all of our experience with summation tests, the ability of the tone to disrupt suppression to the light was small, even for Group 0-.8, we expected even smaller effects in Group .1-.8 of the present experiment. To circumvent this expected difficulty, we took two steps. First, we increased the number of rats assigned to the $.1-.8$ condition from 6 (in Experiment 2) to 16 in an effort to improve statistical sensitivity to the small differences anticipated. Second, we made the flashing light CS more similar to that used by Rescorla (1969a), in yet another effort to increase suppression to the light so that opposition to that suppression could be more readily detected.

\section{Method}

\section{Subjects and Apparatus}

Sixteen naive male albino rats, similar to those of Experiment 1 , served in the same apparatus but with a modified flashing light system. With this system, the $28-\mathrm{V}$ cue light was not used at all. Instead, a 7.5-W $110-\mathrm{V}$ ac frosted bulb was mounted on the rear wall of the housing chamber at the level of the lid of the Skinner box. A large sheet of aluminum foil attached to the rear wall helped to reflect the light, which shone through the right-hand clear plastic wall of the Skinner box when used as a CS. When the light CS was not used, the box was totally dark.

\section{Procedure}

Preliminary training, inhibitory conditioning to the tone, and recovery of barpressing proceeded as in Experiment 2. All rats received the $.1-.8$ negative correlation treatment. 
Following recovery, all rats received forward conditioning to a flashing light while responding for sucrose delivered on a VI 2-min schedule. On each of 6 days of light conditioning, four 2-min presentations of a $1 / \mathrm{sec}$ flashing light were superimposed on responding. During the first 4 days, either the odd CS trials or the even CS trials terminated with the onset of a .5-sec 1-mA grid shock; during the last 2 days, all four daily trials were similarly reinforced.

Following light conditioning were 2 days of summation tests identical to those of Experiment 2. For half the rats, the order of light and light + tone compound test stimuli was light, compound, compound, light on Test Day 1 and compound, light, light, compound on Test Day 2. For the remaining rats these orders were reversed.

\section{Results and Discussion}

Suppression to the light increased over the 6 days of light conditioning; and, by the 6th day, the mean suppression ratio for the 16 rats was .10 .

On the 1st day of summation testing, the mean suppression ratio to the light was $.18,{ }^{2}$ that to the compound was .23. On the 2 nd day of summation testing, the mean suppression ratio to the light was .28 , that to the compound was .32 . Thus, the tone appeared to weaken suppression to the light; but, as anticipated, the effect was very small. Even so, Wilcoxon signed ranks tests showed suppression to the light + tone compound to be significantly weaker than suppression to the light both on Test Day 1 $(\mathrm{T}=26, \mathrm{~N}=15, \mathrm{p}=.028)$ and when the data were averaged over both test days $(\mathrm{T}=24.5, \mathrm{~N}=$ $15, p<.025)$. These same differences were also reliable when the data for the 16 rats of Experiment 3 were combined with those from the 6 rats that received the $.1-.8$ negative correlation treatment in Experiment 2 (ps $<.025)$. It appears, therefore, that the $.1-.8$ negative correlation yields a CS that shows retarded acquisition of excitation (Experiment 1) and opposes excitation in a summation test (present experiment).

\section{GENERAL DISCUSSION}

Rescorla's (1969a) parametric manipulations of the degree of negative correlation were not entirely symmetrical with his earlier manipulations of positive correlations (Rescorla, 1968). In the present work, we attempted to improve the symmetry. While Rescorla (1968) held constant the US rate in CS presence while manipulating that rate in CS absence, we did the reverse. We tried to answer two questions: Would a nonzero rate of USs in CS presence totally destroy conditioned inhibition? Are the effects of positive and negative correlations really symmetrical?

With regard to the first question, the results from our .1-.8 treatment suggest that a nonzero rate of USs in CS presence will not necessarily destroy conditioned inhibition. This treatment produced both retarded acquisition to the tone $\mathrm{CS}$ and disrupted the excitatory effects of a light CS when the tone was compounded with the light. The retarded acquisition did not appear to be due to a simple UShabituation effect because the retardation was specific to the CS that was negatively correlated with the US and did not occur to a novel stimulus. Nor did the retardation appear to be due to a lack of attention to the CS produced by CS preexposure; for, to have disrupted the excitatory effects of the light in the summation test, the tone must have been attended to. Perhaps, however, the retardation was due to reduced attention, not to lack of attention. Perhaps the tone would have disrupted suppression to the light even more in a naive control group than in the .1-.8 group. Although our final experiment did not contain a naive control group, Experiment 2 and the summation savings experiment that preceded Experiment 3 did. In both of those experiments, naive control groups suppressed equally to the light and to the light + tone compound on the 1st day of summation testing. So it does not seem plausible that attention to the tone in the $1-.8$ group was reduced relative to that in the naive group and that this reduced attention was responsible for the retardation. The most plausible interpretation of the data is that the .1-.8 negative correlation left the CS inhibitory. If this interpretation is correct, then for the first time, in fear conditioning at least, conditioned inhibition would have been demonstrated in a negative correlation treatment in which CSs and USs were not entirely explicitly unpaired. (For a comparable demonstration in an appetitive case, see Hearst \& Franklin, 1977).

With regard to the second question posed by this research, the results are mixed. If the effects of negative and positive CS-US correlations are symmetrical, then our results with negative correlations should have paralleled Rescorla's (1968) results with positive correlations. In some respects, the results indeed were parallel. Thus, just as Rescorla (1968) found that excitatory conditioning declined as the US rate in CS absence increased, we found that inhibitory conditioning declined as the US rate in CS presence increased. In other respects, however, the results were not parallel. Thus, Rescorla found evidence for excitatory conditioning resulting from all of his positive correlations, including those as small as .4-.2. In contrast, we could not detect conditioned inhibition following all of our negative correlations, including those as large as .2-.8. Perhaps this means only that our measures of inhibition were not as sensitive as Rescorla's measures of excitation. Nevertheless, our .6-.8 negative correlation not only failed to produce an inhibitory CS but actually left the CS mildly excitatory, at least as measured by a summation test. This result, together with previous demonstrations (Ayres et al., 1975) that slightly negative 
correlations can produce apparently excitatory CSs, may suggest an asymmetry in the effects of positive and negative CS-US correlations. Thus, we know of no comparable experiments in which inhibitory conditioning has been produced by slightly positive, or even zero, correlations.

If positive and negative CS-US correlations have asymmetrical effects, there would appear to be two general theoretical approaches one might take. One approach would explain away such asymmetries as procedural artifacts. Quinsey (1971) discussed this possibility in one of the early demonstrations that truly random control procedures (Rescorla, 1967) can yield apparently excitatory CSs. Quinsey noted that even though one might program a zero withinsession correlation, a positive between-session correlation might still exist. This positive correlation would arise whenever an experiment involved sessions without CSs and USs, together with sessions containing random and independent presentations of CSs and USs. Time in the home cage without USs would also be a factor in establishing this betweensessions correlation. Animals in such experiments might learn that USs occurred only in sessions containing CSs, even though the within-session correlation was zero. Applied to our work, Quinsey's observation suggests that positive between-session correlations could have offset the inhibition-producing effects of the negative correlations we programmed. These positive between-session correlations might, in fact, have been so powerful as to produce the apparent excitation in our .6-.8 condition of Experiment 2 and in several of the slightly negative correlation treatments of Ayres et al. (1975). Consideration of between-session correlations, then, gives the cognitive, correlation-learning theorist a means of predicting that within-session negative correlations should be "harder to learn about" than within-session positive correlations.

An alternative to explaining away ostensible asymmetries under the assumption that none really exist is to turn to theories which postulate asymmetries. One well-known theory with an implied asymmetrical relation between excitation and inhibition is the Rescorla-Wagner model (Rescorla \& Wagner, 1972). In this model, a stimulus becomes inhibitory when it is nonreinforced in compound with excitatory cues, including background apparatus cues. Thus, excitation must always precede inhibition. In addition, the rate of growth of inhibition is determined by a parameter that is generally assumed to be smaller than the growth parameter related to excitation (cf. Rescorla \& Wagner, 1972, p. 88). This means that excitation should approach its asymptote at a faster rate than should inhibition. The model would hold, therefore, that the excitation produced by our .6-.8 treatment and by the slightly negative correlations of Ayres et al. (1975) was a preasymptotic effect. With more extensive training, these treatments would ultimately produce conditioned inhibition. Although we have not tested this prediction here, we have tested a similar prediction elsewhere in another context (Keller, Ayres, \& Mahoney, 1977). In that work, brief exposures to zero correlations, that is, truly random training, yielded highly excitatory CSs; longer exposures, however, significantly weakened that excitation. This result cannot be explained in terms of between-session positive correlations because those correlations existed even for groups that received extended truly random training.

Preasymptotic excitation, followed by a decline in excitation, followed by conditioned inhibition asymptotically, also appears to be a characteristic of backward conditioning (see, e.g., Heth, 1976). If the CS does not begin until after the US terminates, then the CS-US correlation is unquestionably negative: USs never occur in CS presence but do in CS absence. Backward conditioning, therefore, is another case of a negative correlation that produces a preasymptotic excitatory effect. Again, this excitation cannot be explained away in terms of a betweensessions positive correlation. Such a correlation has existed, to be sure, in experiments demonstrating excitatory backward conditioning; but it also existed in those experiments for control groups that received CSs and USs explicitly unpaired (see, e.g., Mahoney \& Ayres, 1976; Mowrer \& Aiken, 1954). For these control groups, the CSs were significantly less excitatory.

We conclude that when CSs and USs are temporally contiguous, even if negatively correlated, an excitatory bias exists preasymptotically. The continued development of theories of learning containing principles from which such biases may be deduced should therefore be favored over those that do not.

\section{REFERENCES}

Annau, Z., \& Kamin, L. J. The conditioned emotional response as a function of intensity of the US. Journal of Comparative and Physiological Psychology, 1961, 54, 428-432.

Ayres, J. J. B., Benedict, J. O., \& Witcher, E. S. Systematic manipulation of individual events in a truly random control in rats. Journal of Comparative and Physiological Psychology, 1975, 88, 97-103.

Halgren, C. R. Latent inhibition in rats: Associative or nonassociative? Journal of Comparative and Physiological Psychology, 1974, 86, 74-78.

Hearst, E., \& Franklin, S. R. Positive and negative relations between a signal and food: Approach-withdrawal behavior to the signal. Journal of Experimental Psychology: Animal Behavvior Processes, 1977, 3, 37-52.

Heth, C. D. Simultaneous and backward fear conditioning as a function of number of CS-UCS pairings. Journal of Experimental Psychology: Animal Behavior Processes, 1976, 2, 117-129.

Hollander, M., \& Wolfe, D. A. Nonparametric statistical methods. New York: Wiley, 1973.

Keller, R. J., Ayres, J. J. B., \& Mahoney, W. J. Brief versus extended exposure to truly random control procedures. 
Journal of Experimental Psychology: Animal Behavior Processes, 1977, 3, 53-65.

Lubow, R. E., \& Moore, A. U. Latent inhibition: The effect of nonreinforced preexposure to the conditioned stimulus. Journal of Comparative and Physiological Psychology, 1959, 52, 415-419.

Lubow, R. E., Rifkin, B., \& Alek, M. The context effect: The relationship between stimulus preexposure and environmental preexposure determines subsequent learning. Journal of Experimental Psychology: Animal Behavior Processes, 1976, 2, 38-47.

Mackintosh, N. J. The psychology of animal learning. New York: Academic Press, 1974.

Mahoney, W. J., \& Ayres, J. J. B. One-trial simultaneous and backward fear conditioning as reflected in conditioned suppression of licking in rats. Animal Learning \& Behavior, 1976, 4, 357-362.

Mis, F. W., \& Moore, J. W. Effect of preacquisition UCS exposure on classical conditioning of the rabbit's nictitating membrane response. Learning and Motivation, 1973, 4, 108-114.

Mowrer, O. H., \& Aiken, E. G. Contiguity vs. drive-reduction in conditioned fear: Temporal variations in conditioned and unconditioned stimulus. American Journal of Psychology, $1954,67,26-38$

Pavlov, I. P. Conditioned reflexes. New York: Dover, 1960.

Quinsey, V. L. Conditioned suppression with no CS-US contingency in the rat. Canadian Journal of Psychology, 1971, 25, 69-82.

REBERG, D. Compound tests for excitation in early acquisition and after prolonged extinction of conditioned suppression. Learning and Motivation, 1972, 3, 246-258.

Reiss, S., \& WAGNer, A. R. CS habituation produces a "latent inhibition effect" but no active "conditioned inhibition." Learning and Motivation, 1972, 3, 237-245.

Rescorla, R. A. Pavlovian conditioning and its proper control procedures. Psychological Review, 1967, 74, 71-80.

Resconla, R. A. Probability of shock in the presence and absence of CS in fear conditioning. Journal of Comparative and Physiological Psychology, 1968, 66, 1-5.
Rescorla, R. A. Conditioned inhibition of fear resulting from negative CS-US contingencies. Journal of Comparative and Physiological Psychology, 1969, 67, 504-509. (a)

Rescorla, R. A. Pavlovian conditioned inhibition. Psychological Bulletin, 1969, 72, 77-94. (b)

Rescorla, R. A. Summation and retardation tests of latent inhibition. Journal of Comparative and Physiological Psychology, 1971, 75, 77-81.

Rescorla, R. A., \& Wagner, A. R. A theory of Pavlovian conditioning: Variations in the effectiveness of reinforcement and nonreinforcement. In A. H. Black \& W. F. Prokasy (Eds.), Classical conditioning II: Current research and theory. New York: Appleton-Century, 1972.

WaGner, A. R. Priming in STM: An information processing mechanism for self-generated or retrieval-generated depression in performance. In T. J. Tighe \& R. N. Leaton (Eds.), Habituation: Perspectives from child development, animal behavior, and neurophysiology. Hillsdale, N.J: Erlbaum, 1976.

WILcoxon, F., \& WILcox, R. Some rapid approximate statistical procedures. Pearl River, N.Y: Lederle Laboratories, 1964.

\section{NOTES}

1. Throughout this research, the direction of differences could be anticipated from theoretical and/or empirical considerations; thus their reliability was assessed using one-tailed tests.

2. This value is similar to the values shown in Table 1 for the rats of Experiment 2. Thus, the modification in our light system did not increase suppression to the light as we had hoped. Our excitatory conditioning, then, was consistently weaker than that of Rescorla (1969a). Since our procedures and parameters were very similar to his, we are inclined to believe that his high-voltage shock source and relay-sequencing scramblers may produce a more effective shock than our Grason-Stadler shockers and scramblers.

(Received for publication December 13, 1978; accepted April 15, 1979.) 